\title{
ATTENTION : MEMBERS
}

\section{OFFICE OF THE DIRECTOR OF INCOME TAX (EXEMPTION) \\ 10B, MIDDLETON ROW ( $6^{\mathrm{TH}}$ FLOOR), KOLKATA-71}

No. DIT(E)/1615

Dated: 24-03-2005

$8 \mathrm{E} / 141 / 1982-83$

Sub: Certificate for the exemption u/s.80G (5)(VI) of the I.T.Act, 1961 (Renewal).

Certified that donation made to Operational Research Society of India, 39 Mahanirvan Road, Kolkata - 700029 shall qualify for deduction u/s. 80G of the Income Tax Act, 1961 subject to the limits prescribed therein.

2. This exemption is valid for A. Y. 2004-05 to 2008-09 and subject to the following conditions:-

i) Receipt issued to the donors should bear the number and date of this order and should state the date up to which this Certificate is valid.

ii) The Income \& Expenditure accounts and balance-sheet should be submit ted annually to the $\mathrm{ADIT}(\mathrm{E}) / \mathrm{ITO}(\mathrm{E})$ having jurisdiction over the case.

iii) The amendments, if any date to the Trust Deed or Memorandum of Association should be intimated to this office and the concerned ADIT(E)/ITO(E) immediately whenever made.

vi) If any further renewal is required, the application should be made to the concerned DIT(E)/CIT in Form No. 10G (See Rule $11 \mathrm{AA}$ ) in triplicate together with relevant particulars/documents.

$S d-$

(BRATATI MUKHERJEE)

DIRECTOR OF INCOME TAX (EXEMPTION)

KOLKAFA 